\title{
Humic acid mediates iron release from ferritin and promotes lipid peroxidation in vitro: a possible mechanism for humic acid-induced cytotoxicity
}

\author{
Received: 16 January 2002 / Accepted: 13 June 2002 / Published online: 17 December 2002 \\ (C) Springer-Verlag 2002
}

\begin{abstract}
Humic acid (HA) has been shown to be a toxic factor for many mammalian cells, however the specific mechanism of the cytotoxicity induced by HA remains unclear. From the assessment of its redox properties, HA has been shown to be capable of reducing iron(III) to iron(II) in aqueous conditions over a broad range of $\mathrm{pH}$ values (from 4.0 to 9.0). By using thiobarbituric acid-reactive substances as an index, the presence of HA was noted to increase the extent of lipid peroxidation both for linoleic acids and within rat liver microsomes. In addition, the increase in HA-induced lipid peroxidation is partially inhibited by sodium azide (a singlet oxygen scavenger) or disodium 4,5-dihydroxy-1,3-benzene-disulfonic acid (a superoxide scavenger), reflecting the involvement of singlet oxygen and superoxide in the process of lipid peroxidation. The addition of HA into a reaction system has been shown to generate superoxide in a dose-dependent manner by the superoxide dismutase-inhibitable cytochrome $c$ reduction assay. In addition, HA is able to reduce and release iron from ferritin, but this process is partially inhibited by superoxide scavengers. Subsequently, the iron released from ferritin was shown to accelerate the HA-induced lipid peroxidation. From our results we conclude that HA has the ability to reduce and release iron from ferritin storage as well as to promote lipid peroxidation. Therefore, HA
\end{abstract}

\author{
K.-J. Ho · F.-J. Lu ( $ه)$ \\ Graduated Institute of Biochemistry and Molecular Biology, \\ College of Medicine, National Taiwan University, \\ Taipei, Taiwan, Republic of China \\ E-mail: fujulu@ha.mc.ntu.edu.tw \\ Tel.: + 886-2-23123456 ext 8208 \\ Fax: + 886-2-23214559 \\ T.-K. Liu \\ Department of Geosciences, National Taiwan University, \\ Taipei, Taiwan, Republic of China \\ T.-S. Huang \\ Department of Medicine, College of Medicine, \\ National Taiwan University, Taipei, Taiwan, \\ Republic of China
}

coupled with released iron can disturb the redox balance and elicit oxidative stress within a biological system. This may be one of the most important mechanisms for HA-induced cytotoxicity.

Keywords Humic acid Lipid peroxidation S Superoxide Iron · Ferritin

\section{Introduction}

Humic acid (HA) is a dark-colored and heterogeneous mixture of organic material ubiquitously existing in terrestrial and aquatic environments. According to its basic definition, HA consists of the fraction of humic substances that is precipitated from aqueous alkaline extracts of soil when the $\mathrm{pH}$ is decreased below 2 (Hayes et al. 1989). Hence, HA may well be present in solution in natural waters. A number of studies have conducted spectroscopic analyses of HA in order to characterize its chemical structure (Rex 1960; Atherton et al. 1967; Schnitzer and Skinner 1969; Wilson et al. 1978; Worobey and Webster 1981; Huffman and Stuber 1985; Leenheer and Noyes 1989). Nuclear magnetic resonance (NMR) and infrared (IR) spectroscopic analyses have revealed that HA consists of a series of aromatic rings, with attached phenolic hydroxyl, ketone carbonyl, quinone carbonyl, carboxyl, and alkoxyl functional groups (Wilson et al. 1978; Worobey and Webster 1981; Huffman and Stuber 1985; Leenheer and Noyes 1989). In addition, on the basis of electron spin resonance (ESR) spectra analyses, HA is believed to be a semiquinonetype radical (Rex 1960; Atherton et al. 1967; Schnitzer and Skinner 1969). Since quinone and phenolic groups in HA are located close to one another, free radicals in HA are both "trapped" and "caged" and become more stable than other semiquinone-type free radicals. As a consequence of such physico-chemical properties, HA is known to exhibit electron-transfer reactions within itself or between HA and other substances, and it also seems to exhibit some redox capability. 
Several previous studies have considered the redox properties of HA (Szilagyi 1973a, 1973b; Skogerbae and Wilson 1981; Loveley et al. 1996). The normal reduction potential $\left(E^{0}\right)$ for $\mathrm{HA}$ in a peat-water system is $0.7 \mathrm{~V}$ compared to the normal hydrogen electrode (NHE) (Szilagyi 1973a). Since HA possesses a lower $E^{0}$ value than that for iron(III) $\left(E^{0}=0.771 \mathrm{~V}\right)$, it is capable of reducing iron(III) to iron(II) in vitro (Szilagyi 1973b) or in iron(III)-reducing bacteria (Loveley et al. 1996). In the iron(III)-reducing bacterium Geobacter metallireducens, HA seems to be a potential electron acceptor when acetate serves as the sole electron donor. The quinone moieties of HA may be the electron-accepting groups, with the resultant hydroquinones donating electrons to an ultimate electron acceptor such as iron(III), such that the ability of HA to participate in such an electron transfer system may thus be based on its quinone/ hydroquinone redox couple (Loveley et al. 1996).

Iron is a redox-active transition metal; that is, it may readily oscillate between the ferrous and ferric states, accepting an electron from or donating an electron to a variety of biological substances. Iron is necessary for cell functions due to its role in major biological reactions such as the tricarboxylic acid cycle, electron transport pathway, and toxication and detoxication reactions (Ponka et al. 1998). However, excess iron can disturb the redox balance of biological systems and trigger deleterious reactions such as the degradation of proteins and nucleic acids, or the oxidative breakdown of polyunsaturated fatty acids. Hence, iron metabolism must be tightly controlled and regulated by the cells. The iron storage protein, ferritin, plays a key role in the iron metabolism process, in that it is able to sequester iron in a relatively inert form until the iron is needed for critical iron-dependent metabolic processes (Harrison and Arosio 1996). The iron within ferritin exists as a hydrous ferric oxide core that may contain as many as 4,500 atoms of Fe per molecule, but which is normally only 20\% saturated (Reif 1992; Harrison and Arosio 1996). The release of iron from ferritin requires reduction in the presence of suitable reductants. Although the endogenous physiological reductant is unknown, the redoxcycling xenobiotics have been found to release ferritin iron directly via electron transfer or indirectly via the superoxide generated by the xenobiotics themselves; such xenobiotics consist of species such as alloxan (Reif et al. 1989), paraquat (Thomas and Aust1986) and 1,2,4benzenetriol (Ahmad et al. 1995). Iron released from ferritin by these xenobiotics has been shown to catalyze lipid peroxidation.

HA, a xenobiotic radical with redox properties, has been shown to be a toxic factor for many mammalian cells, including endothelial cells (Chiu et al. 1993), chondrocytes (Liang et al. 1998, 1999) and erythrocytes (Cheng et al. 1999). In our previous studies, HA was also noted to be responsible for a variety of functional changes such as enhancing the expression of tissue factor in cultured endothelial cells (Yang et al. 1994), shortening plasma prothrombin time ( $\mathrm{Lu}$ and Lee 1992), inhibiting hepatic thyroxine 5'-monodeiodinase activities (Huang et al. 1993), inducing blackening of the tail and feet in mice ( $\mathrm{Lu}$ and Liu 1986; Lu 1990a, 1990b), and eliciting testicular morphological changes in rats ( $\mathrm{Lu}$ et al. 1997). The mechanisms of cellular injury and oxidative damage induced by HA, however, are not well understood. The aim of the present study was to investigate the ability of HA to reduce and release iron from ferritin storage as well as to promote lipid peroxidation. The potential for HA to reduce iron and induce lipid peroxidation may be an important toxic mechanism in vivo.

\section{Materials and methods}

Chemicals

Humic acid (sodium salt, technical grade) was obtained from Aldrich Chemical Co. (Milwaukee, Wis., USA). It was further purified by an alkaline-acid treatment and subsequent ultrafiltration as indicated below. $o$-Phenanthroline (OP), linoleic acid, thiobarbituric acid (TBA), sodium azide $\left(\mathrm{NaN}_{3}\right)$, mannitol, disodium 4,5-dihydroxy-1,3-benzene-disulfonic acid (Tiron), butylated hydroxytoluene (BHT), 2,2,6,6-tetramethyl-1-piperidinyloxy (TEMPO), superoxide dismutase (SOD), catalase, and horse spleen ferritin were obtained from Sigma Chemical Co. (St. Louis, Mo., USA). All other chemicals and solvents used in this study were of analytical grade and were supplied by Sigma Chemical Co.

\section{Purification of Aldrich humic acid}

All of the experiments, with the exception of spectroscopic analyses, were performed with the same batch of humic acid (HA) purified from the commercially available HA from Aldrich. Our purification method was similar to that described by Schnitzer (1982) and consisted of the following steps. The HA was first dissolved in $0.1 \mathrm{~N} \mathrm{NaOH}$ solution, and any undissolved material was removed by centrifuging for $30 \mathrm{~min}$ at $10,000 \mathrm{~g}$. The supernatant was slowly acidified to $\mathrm{pH} 1.0$ with concentrated $\mathrm{HCl}$. The precipitate of HA so elicited was centrifuged and re-dissolved in $0.1 \mathrm{~N}$ $\mathrm{NaOH}$. This procedure of alkali-acid treatment was repeated three times to remove non-humic materials and the iron remained in the HA phase. After the third round of acid precipitation, the precipitate was dissolved in $0.1 \mathrm{~N} \mathrm{NaOH}$, and the $\mathrm{pH}$ value of the resultant solution was then adjusted to between 7.2 and 7.4. The resultant humic solution was ultrafiltered on a Molecular/Por membrane $(<1,000 \mathrm{Da}$, molecular weight excluded $)$ in a stirred cell in order to desalt and concentrate the solution. The retentate was dried with a rotary evaporator, and the resultant purified HA powder was stored in a desiccator under vacuum. Elemental analysis of the purified HA gave values of $\mathrm{C} 42.25 \%, \mathrm{H} 4.27 \%, \mathrm{~N}$ $0.81 \%$.

\section{Determination of reduction potentials $\left(E_{\mathrm{h}}\right)$}

For the evaluation of the reduction potentials of HA and iron(III), the concentrations of $\mathrm{HA}$ and ferric chloride $\left(\mathrm{FeCl}_{3}\right)$ used were held constant at $400 \mu \mathrm{g} / \mathrm{ml}$ and $50 \mu \mathrm{M}$, respectively. All test solutions were initially adjusted to a $\mathrm{pH}<4.0$ and then readjusted to the required values ( $\mathrm{pH} 4.0$ to 9.0 ) for each particular test study. The reduction potentials of $\mathrm{HA}$ and iron(III) preparations were carried out with a microprocessor ORP/pH meter (Hanna model: HI9017) to determine the $E_{\mathrm{h}}-\mathrm{pH}$ relationship. 
Determination of iron(III) reduction

To determine the extent of reduction of iron(III) by HA, the mixtures of $\mathrm{HA}$ and $\mathrm{FeCl}_{3}$ were prepared at a constant concentrations of $400 \mu \mathrm{g} / \mathrm{ml}$ and $50 \mu \mathrm{M}$, respectively. All test solutions were initially adjusted to a $\mathrm{pH}<4.0$ and then readjusted to the required values ( $\mathrm{pH} 4.0$ to 9.0) for each particular test study. All solutions were prepared in acid-washed flasks that were covered with aluminum foil to avoid exposure to light. The test solutions were bubbled with nitrogen for $5 \mathrm{~min}$, and were then covered tightly with parafilm to exclude air and allowed to stand at room temperature for $24 \mathrm{~h}$ prior to analysis.

The iron(II) concentrations produced by reaction of iron(III) and HA were determined by the $o$-phenanthroline (OP) method described by Sandell (1959) with some modifications. In brief, all test solutions were adjusted to a $\mathrm{pH}<1.0$ with concentrated $\mathrm{HCl}$ to break the interaction between HA and iron, and the solutions were then centrifuged at $10,000 \mathrm{~g}$ for $10 \mathrm{~min}$ to remove the precipitated HA. The supernatants were readjusted to $\mathrm{pH} 4.0$ for the iron(II) determinations. Aliquots of $0.5 \mathrm{ml} \mathrm{OP}(0.3 \%)$ solution were placed in $1.5-\mathrm{ml}$ Eppendorf tubes together with $0.5 \mathrm{ml}$ of the supernatants from the iron-HA test solutions, and the color was allowed to develop in the dark for $24 \mathrm{~h}$. The absorbance values of all test solutions were recorded at $508 \mathrm{~nm}$ and calibrated with ferrous sulfate solutions as standards, treated in parallel according to the same procedures.

To determine the reduction rates of iron(III) by HA, the reaction mixtures of $\mathrm{OP}$ and $\mathrm{FeCl}_{3}$ were prepared at constant concentrations of $0.06 \%$ and $100 \mu \mathrm{M}$, respectively. Reactions were started by the addition of various concentrations of $\mathrm{HA}(0,50,100$, 150 , or $200 \mathrm{pg} / \mathrm{ml}$ ), and the change in absorbance was measured continuously at $508 \mathrm{~nm}$ for the initial $10 \mathrm{~min}$ of reaction. The rates of iron reduction by HA were expressed as nanomoles Fe per minute.

Preparation of liver microsomes

Male Wistar rats weighing 200-250 g were decapitated, and the livers were rapidly removed and washed. One gram of rat liver was homogenized in $9 \mathrm{ml}$ of ice-cold $3 \mathrm{mM}$ ethylenediaminetetraacetic acid and $154 \mathrm{mM} \mathrm{KCl}$, maintained at a $\mathrm{pH}$ of 7.4. The homogenate was centrifuged at $10,000 \mathrm{~g}$ for $20 \mathrm{~min}$, and then the supernatant was separated and centrifuged at $105,000 \mathrm{~g}$ for $60 \mathrm{~min}$. After protein analysis by the method of Lowry (1951), microsomes were immediately used in the experiments.

\section{Lipid peroxidation assay}

Solutions of $0.4 \mathrm{mM}$ linoleic acids or $0.2 \mathrm{mg}$ protein $/ \mathrm{ml}$ liver microsomes were incubated with various treatments (HA with antioxidants mannitol, $\mathrm{NaN}_{3}$, Tiron, BHT, or TEMPO, or with $\mathrm{Fe}^{2+}$ or $\mathrm{Fe}^{3+}$, as outlined in Figs. 3, 4 and Table 1) in phosphate-buffered saline (PBS, $\mathrm{pH} 7.4$ ) at $37^{\circ} \mathrm{C}$ for $1 \mathrm{~h}$. The total volume of incubation mixture was $1 \mathrm{ml}$. Then the extent of lipid peroxidation in the reaction mixture was determined by the colorimetric thiobarbituric acid (TBA) method. In brief, to this reaction mixture was added $100 \mu \mathrm{H}_{3} \mathrm{PO}_{4}(0.44 \mathrm{M})$ and $200 \mu \mathrm{l}$ TBA $(0.67 \%)$, and the solution was heated to a constant $95^{\circ} \mathrm{C}$ for $60 \mathrm{~min}$. After addition of $200 \mu \mathrm{l}$ trichloroacetic acid $(20 \%)$, the reaction mixture was centrifuged at $10,000 \mathrm{~g}$ for $10 \mathrm{~min}$ to enable the precipitation of proteins or HA. The extent of TBAreactive substances (TBARS) within the supernatant was determined by measuring the absorbance at $532 \mathrm{~nm}$. A standard concentration curve was generated using malondialdehyde derived by acid hydrolysis of 1,1,3,3-tetraethoxypropane. In the experimental model involving ferrous/ferric ions, the metal ions were included in the incubation mixture at a concentration of $50 \mu \mathrm{M}$. Iron solutions were prepared freshly in distilled water and used immediately.

\section{Determination of superoxide formation}

Superoxide formation was measured by a SOD-inhibitable cytochrome $c$ reduction assay. In brief, the reaction mixture contained $100 \mu \mathrm{M}$ cytochrome $c$ with or without SOD in PBS. The incubation was started by the addition of various concentrations of $\mathrm{HA}$, and the absorption at $550 \mathrm{~nm}$ was continuously measured at $37^{\circ} \mathrm{C}$ for the initial $10 \mathrm{~min}$ of reaction. The superoxide formation was calculated from the increase in the absorbance at $550 \mathrm{~nm}$ by using an extinction coefficient of $21,400 \mathrm{M}^{-1} \mathrm{~cm}^{-1}$ for cytochrome $c$. The rates of superoxide formation were expressed as nanomoles product per $10 \mathrm{~min}$.

\section{Iron release assay}

Aliquots of horse spleen ferritin were diluted in a ten-fold volume of deionized distilled water and were ultrafiltered using a Millipore Centricon filter with a molecular weight cutoff of 10,000 Da. The same procedure was repeated three times to remove unbound iron, ferritin being subsequently redissolved in PBS to give a final concentration of $10 \mathrm{mg} / \mathrm{ml}$. These solutions were stored on ice and used immediately for iron release assay. The reduction and release of iron from ferritin was measured using $\mathrm{OP}$ as an iron chelator. Ferritin, $500 \mu \mathrm{g} / \mathrm{ml}$, was incubated at $37^{\circ} \mathrm{C}$ in PBS with $0.06 \%$ OP, various concentrations of $\mathrm{HA}(0,50,100,150$, or $200 \mu \mathrm{g} / \mathrm{ml})$ and oxygen radical scavengers (Tiron $10 \mathrm{mM}$, SOD 500 units $/ \mathrm{ml}$, or catalase 500 units $/ \mathrm{ml}$ ). The development of the iron(II)-OP complex was continuously measured with a spectrophotometer at $508 \mathrm{~nm}$ for the first $10 \mathrm{~min}$.

\section{Statistical analysis}

All experiments apart from spectroscopic characterization were performed in triplicate sets and analyzed by the Student's $t$-test or using one-way ANOVA followed by Bonferroni's $t$-test for multiple

Table 1 Effect of antioxidants on humic acid (HA)-induced lipid peroxidation. Linoleic acids $(0.4 \mathrm{mM})$ were incubated with HA $(50 \mu \mathrm{g} / \mathrm{ml})$ in the absence (Control) or the presence of different types of antioxidants in phosphate-buffered saline at $37^{\circ} \mathrm{C}$ for $1 \mathrm{~h}$ prior to assay for thiobarbituric acid-reactive substances (TBARS) as described in Materials and methods section. The antioxidants used were: mannitol, a hydroxy radical scavenger; sodium azide $\left(\mathrm{NaN}_{3}\right)$, a singlet oxygen scavenger; disodium 4,5-dihydroxy-1,3benzene-disulfonic acid (Tiron), a superoxide scavenger; butylated hydroxytoluene (BHT), a chain-breaking agent of lipid peroxidation; 2,2,6,6-tetramethyl-1-piperidinyloxy (TEMPO), a spin trapper. Each value represents the mean $\pm \mathrm{SD}$ of triplicate independent determinations

\begin{tabular}{|c|c|c|}
\hline Treatment & $\begin{array}{l}\text { TBARS } \\
(\mathrm{nmol} / \mathrm{ml})\end{array}$ & $\begin{array}{l}\text { Inhibition } \\
(\%)\end{array}$ \\
\hline Blank (0.4 mM linoleic acid) & $7 \pm 10$ & - \\
\hline $\begin{array}{l}\text { Control }(0.4 \mathrm{mM} \text { linoleic acid }+ \\
50 \mu \mathrm{g} / \mathrm{ml} \mathrm{HA})\end{array}$ & $1772 \pm 116$ & 0 \\
\hline Control $+10 \mathrm{mM}$ mannitol & $1718 \pm 25$ & 3 \\
\hline Control $+5 \mathrm{mM} \mathrm{NaN}_{3}$ & $1348 \pm 120^{*}$ & 24 \\
\hline Control $+10 \mathrm{mM} \mathrm{NaN}_{3}$ & $1328 \pm 79 *$ & 25 \\
\hline Control $+5 \mathrm{mM}$ Tiron & $1124 \pm 77^{*}$ & 37 \\
\hline Control $+10 \mathrm{mM}$ Tiron & $1019 \pm 134^{*}$ & 42 \\
\hline Control $+20 \mathrm{mM}$ Tiron & $939 \pm 27 *$ & 47 \\
\hline $\begin{array}{l}\text { Control }+5 \mathrm{mM} \mathrm{NaN}_{3}+ \\
5 \mathrm{mM} \text { Tiron }\end{array}$ & $884 \pm 111^{*}$ & 50 \\
\hline $\begin{array}{l}\text { Control }+10 \mathrm{mM} \mathrm{NaN}_{3}+ \\
10 \mathrm{mM} \text { Tiron }\end{array}$ & $840 \pm 84^{*}$ & 53 \\
\hline Control $+25 \mu \mathrm{M}$ BHT & $561 \pm 95^{*}$ & 68 \\
\hline Control $+50 \mu \mathrm{M} \mathrm{BHT}$ & $381 \pm 64^{*}$ & 79 \\
\hline Control $+100 \mu \mathrm{M}$ BHT & $81 \pm 91^{*}$ & 95 \\
\hline Control $+5 \mathrm{mM}$ TEMPO & $119 \pm 33^{*}$ & 93 \\
\hline
\end{tabular}

$* P<0.05$, significant difference from the control value 
comparisons, as appropriate. A value of $P<0.05$ was considered a statistically significant.

\section{Results}

Reduction potentials of HA and iron(III) at various $\mathrm{pH}$ values

Humic acid has a redox capability and appears to be a reducing agent of iron. To determine the redox properties of HA and iron, we measured the reduction potentials of $\mathrm{HA}$ and ferric ion preparations upon $\mathrm{pH}$ change in an aqueous phase. The experimentally obtained curves for HA and ferric iron both appeared as a linear function of the $\mathrm{pH}$ change (Fig. 1). Such results revealed that the redox potentials of HA were always lower than the corresponding value for the ferric iron over a $\mathrm{pH}$ range of 4.0-9.0, suggesting that HA should be capable of reducing iron(III) to iron(II) irrespective of the $\mathrm{pH}$ value.

\section{Reduction of iron(III) to iron(II) by HA}

To evaluate the effect of $\mathrm{pH}$ on the iron(III) reduction reaction, we measured the degree of iron reduction for solutions, at each of several $\mathrm{pH}$ values, each containing $\mathrm{HA}$ and $\mathrm{FeCl}_{3}$ at concentrations of $400 \mu \mathrm{g} / \mathrm{ml}$ and $50 \mu \mathrm{M}$ respectively (Fig. 2A). The data indicated a high degree of reduction at $\mathrm{pH} 4.0$, which decreased with increasing $\mathrm{pH}$ values. In addition, to determine the effect of HA concentrations on the rates of iron(III) reduction, a mixture of $\mathrm{FeCl}_{3}(100 \mu \mathrm{M})$ and $\mathrm{OP}(0.06 \%)$ was incubated with various concentrations of $\mathrm{HA}$ ranging from 50 to $200 \mu \mathrm{g} / \mathrm{ml}$ for a period of $10 \mathrm{~min}$ at $25^{\circ} \mathrm{C}$, pH 7.0 (Fig. 2B). The results suggest that the reduction rates of iron(III) induced by HA present in a dosedependent manner.

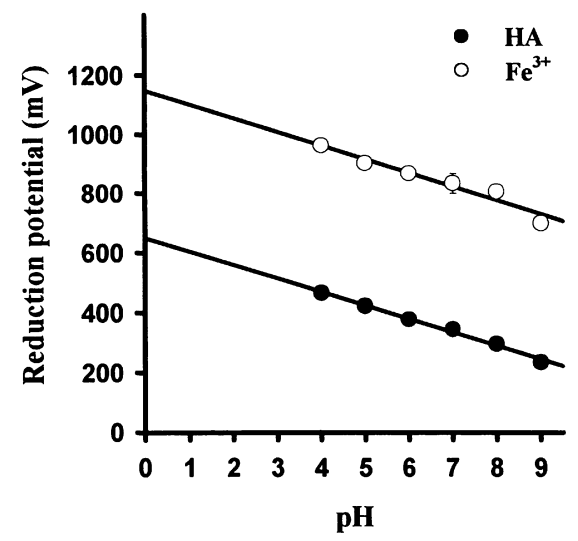

Fig. 1 A comparison of reduction potentials of humic acid (HA) and ferric irons $\left(\mathrm{Fe}^{3+}\right)$ at various $\mathrm{pH}$ values. The concentrations of $\mathrm{HA}$ and ferric chloride were constant at $400 \mu \mathrm{g} / \mathrm{ml}$ and $50 \mu \mathrm{M}$, respectively, and all test solutions were adjusted to the required $\mathrm{pH}$ values ( $\mathrm{pH}$ 4.0-9.0) for each test study. Results are expressed as means \pm SD for three independent experiments
HA-induced lipid peroxidation of linoleic acids and rat liver microsomes

Lipid peroxidation is one of the most important organic expressions of oxidative stress induced by the reactivity of free radicals. The process of lipid peroxidation is initiated by an attack of any chemical species that has sufficient reactivity to abstract a hydrogen atom from a methylene carbon of polyunsaturated fatty acids. It is possible that HA has the capacity to induce lipid peroxidation via its free radicals. In the present study, we investigated the effect of HA on the lipid peroxidation of linoleic acids and in rat liver microsomes using the TBA method. The effect of HA on lipid peroxidation of linoleic acids is shown in Fig. 3A. The increase in lipid peroxidation as measured by the level of TBARS formation has an almost linear relationship with the increase in $\mathrm{HA}$ concentration from 0 to $50 \mu \mathrm{g} / \mathrm{ml}$.
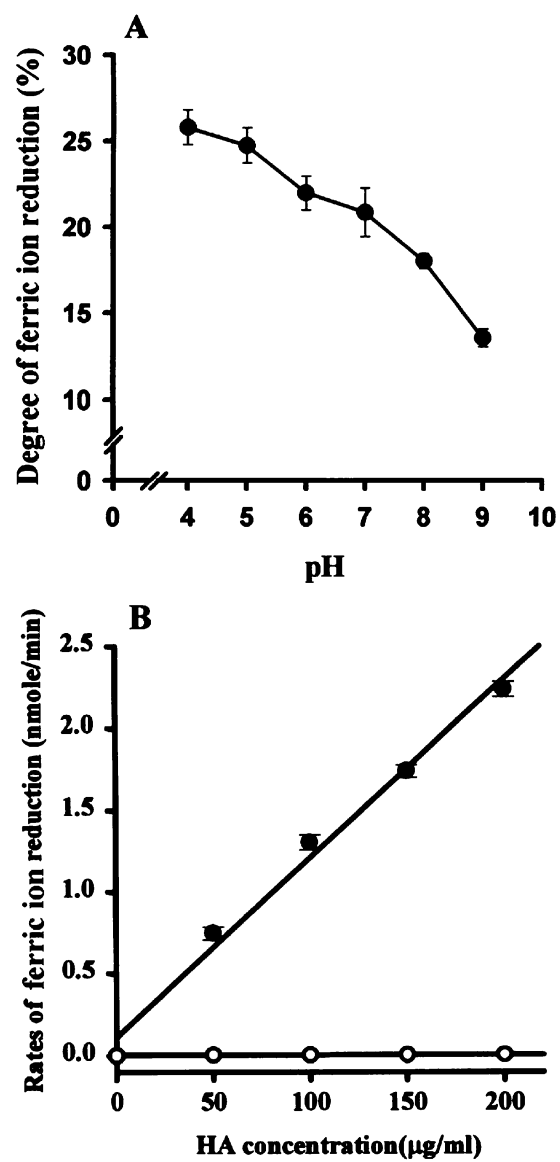

Fig. 2A,B Reduction of iron(III) to iron(II) by humic acid (HA). A Degree of ferric iron reduction induced by $\mathrm{HA}$ at various $\mathrm{pH}$ values. The reaction solutions containing HA $(400 \mu \mathrm{g} / \mathrm{ml})$ and ferric chloride $(50 \mu \mathrm{M})$ were incubated at various $\mathrm{pH}$ values for $24 \mathrm{~h}$ before iron(II) analysis as described in Materials and methods section. B Rates of ferric ion reduction induced by HA in the presence (O) and absence (O) of ferric chloride. A solution containing $o$-phenanthroline $(0.06 \%)$ in the presence or absence of ferric chloride $(100 \mu \mathrm{M})$ was incubated with various concentrations of HA $(0,50,100,150$, or $200 \mu \mathrm{g} / \mathrm{ml})$ for $10 \mathrm{~min}$ at $25^{\circ} \mathrm{C}$. Values are means $\pm \mathrm{SD}$ for three independent experiments 
Thereafter, the TBARS level remained relatively constant with increasing concentrations of HA above $50 \mu \mathrm{g} / \mathrm{ml}$. Similarly, the extent of lipid peroxidation in rat liver microsomes increased markedly at HA concentrations between 30 and $50 \mu \mathrm{g} / \mathrm{ml}$, and in an asymptotic manner toward constant levels with HA concentrations $<30 \mu \mathrm{g} / \mathrm{ml}$ and $>50 \mu \mathrm{g} / \mathrm{ml}$ (Fig. 3B).

Effect of antioxidants on HA-induced lipid peroxidation

The mechanism of HA-induced lipid peroxidation remains unclear. To elucidate such mechanism, we used various kinds of antioxidants in the reaction mixtures. The results indicated in Table 1 represent the effect of antioxidants on HA-induced lipid peroxidation. The normally resultant degree of TBARS formation was partially inhibited in the presence of $\mathrm{NaN}_{3}(25 \%)$ and
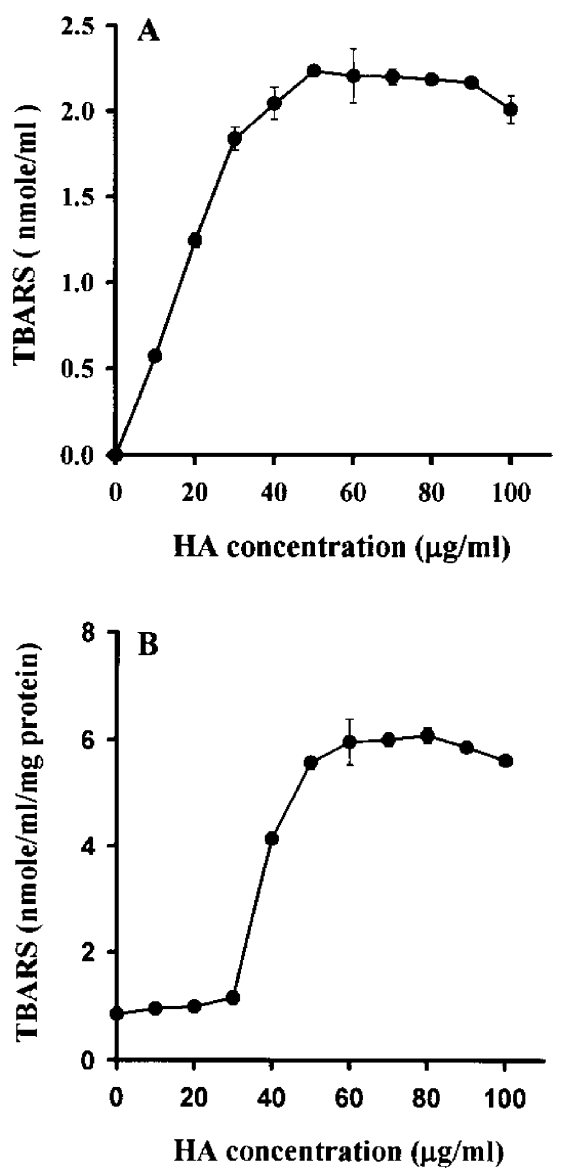

Fig. 3A,B Lipid peroxidation induced by humic acid (HA) on linoleic acids (A) and within rat liver microsomes (B). A solution containing linoleic acids $(0.4 \mathrm{mM})$ or rat liver microsomes $(0.2 \mathrm{mg}$ protein $/ \mathrm{ml})$ was incubated with various concentrations of HA $(0-$ $100 \mu \mathrm{g} / \mathrm{ml}$ ) in phosphate-buffered saline at $37^{\circ} \mathrm{C}$ for $1 \mathrm{~h}$ prior to the analysis of the extent of lipid peroxidation as thiobarbituric acidreactive substances (TBARS) as thiobarbituric acid-reactive substances (TBARS). Values are means \pm SD for three independent experiments
Tiron (42\%), compounds that specifically quench singlet oxygen and superoxide anion radicals, respectively. Co-incubation with both $\mathrm{NaN}_{3}$ and Tiron revealed an additive effect on the inhibition of TBARS formation, the degree of this inhibition approaching 53\%. BHT, a known chain-breaking agent, abolished HA-induced lipid peroxidation in a concentration-dependent manner, whereas TEMPO, which acts as a spin trapper, almost completely inhibited the formation of TBARS, the degree of this inhibition approaching 93\%. However, mannitol, a scavenger of hydroxyl radicals, demonstrated no effect on the extent of HA-induced lipid peroxidation.

\section{Effect of iron on HA-induced lipid peroxidation}

Iron has been shown to initiate lipid peroxidation by autooxidation (Minotti and Aust 1992). The presence of some iron is also needed for the propagation of lipid peroxidation that consists of the decomposition of newly formed lipid hydroperoxides (LOOH) to form alkoxyl radicals. To determine the effect of iron on HA-induced lipid peroxidation, ferrous or ferric ions at concentrations of $50 \mu \mathrm{M}$ were added to the incubation mixture in the presence or absence of $50 \mu \mathrm{g} / \mathrm{ml} \mathrm{HA}$. Such addition of ferrous or ferric ions to an incubation of linoleic acid resulted in a slight increase in the level of TBARS formation (Fig. 4). The extent of lipid peroxidation in reaction mixtures containing $\mathrm{HA}$ and iron (whether present as ferrous or ferric ions), however, was markedly more substantial than in the iron-free control condition.

\section{Superoxide generation by HA}

Humic acid is a polyphenolic compound with redox properties, appearing to exhibit the ability to generate reactive oxygen species. In the lipid peroxidation assay, HA-induced TBARS formation was partially inhibited by the presence of Tiron, indicating that superoxide may participate in this reaction process. To determine whether HA could directly generate superoxide in vitro, we investigated the effect of HA on superoxide generation in a SOD-inhibitable cytochrome $c$ reduction assay. Our results indicate that superoxide was generated by HA in a dose-dependent manner (Fig. 5). In addition, the generation of superoxide by $200 \mu \mathrm{g} / \mathrm{ml} \mathrm{HA}$ was almost completely inhibited by the presence of 500 units/ $\mathrm{ml}$ SOD, superoxide being generated at only $7 \%$ of the level when no SOD was present.

\section{Release of iron from ferritin by HA}

The addition of HA (50-200 $\mu \mathrm{g} / \mathrm{ml})$ to horse spleen ferritin in the presence of OP resulted in the formation of an iron(II)-OP complex; increasing concentrations of HA corresponded to an increase in the production of 


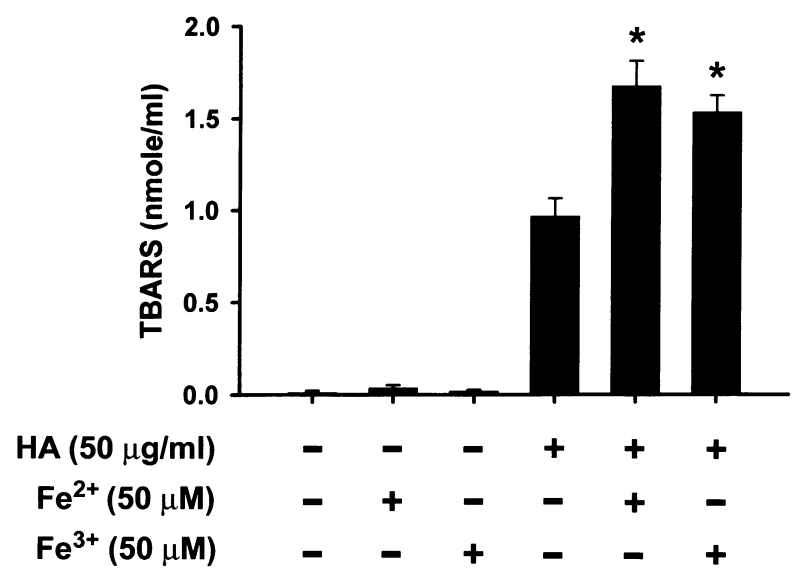

Fig. 4 Effect of iron on humic acid (HA)-induced lipid peroxidation. Linoleic acids $(0.4 \mathrm{mM})$ were incubated with $50 \mu \mathrm{M}$ of ferrous sulfate $\left(\mathrm{Fe}^{2+}\right)$ or ferric chloride $\left(\mathrm{Fe}^{3+}\right)$ at $37^{\circ} \mathrm{C}$ for $1 \mathrm{~h}$ in the presence $(+)$ or absence $(-)$ of $\mathrm{HA}(50 \mu \mathrm{g} / \mathrm{ml})$. A solution containing linoleic acids $(0.4 \mathrm{mM})$ without $\mathrm{HA}$ and iron $\left(\mathrm{Fe}^{2+}\right.$ or $\mathrm{Fe}^{3+}$ ) was used as control. The extent of lipid peroxidation in the reaction solutions was determined as thiobarbituric acid-reactive substances (TBARS) generation as described in Materials and methods section. Values are means \pm SD for three independent experiments. ${ }^{*} P<0.05$, versus the $50 \mu \mathrm{g} / \mathrm{ml} \mathrm{HA}$ group

iron(II)-OP complex, indicating that iron is being released from ferritin (Fig. 6A). In such a reaction, the rate of iron release from ferritin was dependent upon the concentration of HA, revealing a linear relationship over a 10-min incubation period. To investigate the effect of oxygen radical scavengers upon HA-mediated iron release from ferritin, SOD, Tiron, or catalase was included in the incubation mixture. After incubation for $10 \mathrm{~min}$, both SOD (500 units $/ \mathrm{ml}$ ) and Tiron $(10 \mathrm{mM})$ were able to inhibit iron release from ferritin to a level approximately $52 \%$ and $67 \%$, respectively, of control level, whereas the addition catalase (500 units/ $\mathrm{ml}$ ) revealed a small increase in iron release of $20 \%$ (Fig. 6B).

\section{Effect of ferritin on HA-induced lipid peroxidation}

HA has been shown to release iron from ferritin as described above, and ferritin-released iron is likely to accelerate lipid peroxidation induced by HA. The effect of ferritin on HA-induced lipid peroxidation is illustrated in Fig. 7. The addition of ferritin $(10-50 \mu \mathrm{g} / \mathrm{ml})$ to HA resulted in the formation of TBARS, with increasing concentrations of ferritin corresponding to an increase in the production of TBARS, whereas ferritin did not promote any lipid peroxidation in the absence of HA (Fig. 7A). Consistent with the results depicted in Fig. 3A, the levels of TBARS remained relatively constant as concentrations of HA were elevated above $50 \mu \mathrm{g} / \mathrm{ml}$ (Fig. 7B). However, HA at 75 and $100 \mu \mathrm{g} / \mathrm{ml}$ exhibited additional effects upon lipid peroxidation in the presence of ferritin.

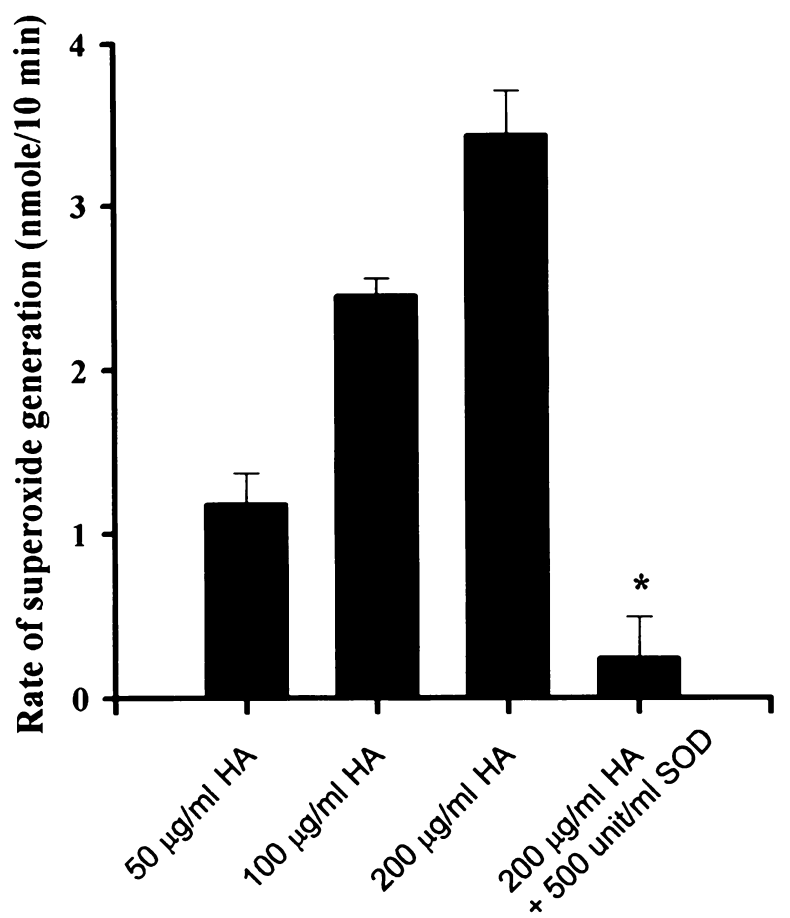

Fig. 5 The ability of humic acid (HA) to directly generate superoxide. Solutions containing HA $(50,100$, or $200 \mu \mathrm{g} / \mathrm{ml})$ were incubated with cytochrome $c(100 \mu \mathrm{M})$ with or without superoxide dismutase (SOD) in phosphate-buffered saline. The degree of superoxide generated by HA is proportional to the increase in absorbance at $550 \mathrm{~nm}$. Each value represents the mean $\pm \mathrm{SD}$ of three separate estimations. ${ }^{*} P<0.05$, versus the $200 \mu \mathrm{g} / \mathrm{ml} \mathrm{HA}$ group

\section{Discussion}

Blackfoot disease (BFD) is an endemic peripheral vascular disease prevailing along the southwest coast of Taiwan (Tseng et al. 1961). Humic acid (HA) in well water used for drinking and cooking by affected local inhabitants is the main likely etiological factor that has been proposed as being responsible for BFD ( $\mathrm{Lu} \mathrm{1990a).}$ Epidemiological and geochemical studies have disclosed the presence of a high concentration of HA (approximately $200 \mathrm{ppm}$ ) in artesian well water from BFDendemic areas (Huang et al. 1994; Lu and Liu 1986). The daily intake of HA by the average resident in these areas has been estimated to be as high as $400 \mathrm{mg}$. It is conceivable that the intake of large quantities of HA has adversely affected the health of inhabitants in these areas, and was conducive to the pathogenesis of BFD. Radioisotope tracing with iodinated HA in rats indicated that up to $60 \%$ of HA remained in the body $24 \mathrm{~h}$ after its administration (Huang et al. 1995). The oxy or hydroxy functional groups in HA can interact with cell membrane proteins and HA remaining thus in the body is not easily cleared. On long-term exposure to HA, it can accumulate and rise to cytotoxic concentrations locally in cells or in some region of body. Thus, an elevated level of blood lipid peroxides has been detected in patients 

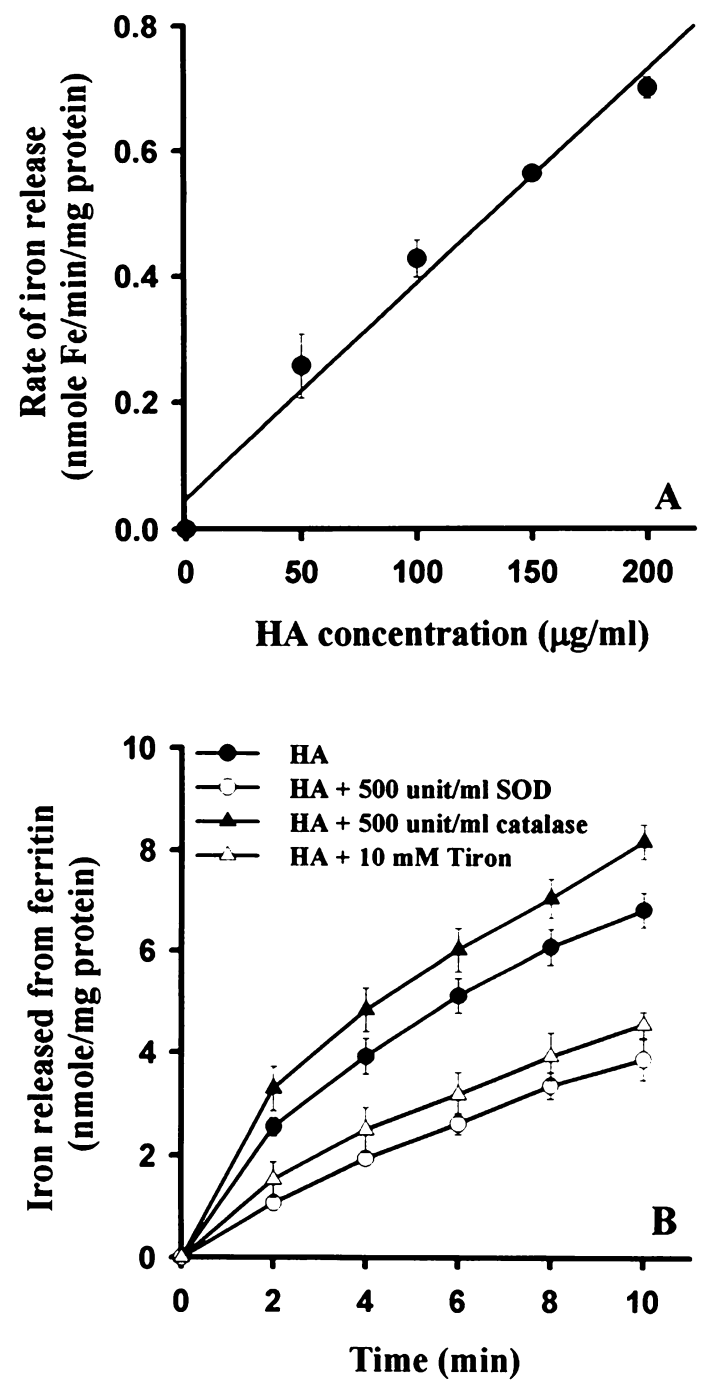

Fig. 6A,B Release of iron from ferritin by humic acid (HA). A Dose-dependence of HA-induced release of iron from ferritin. An aliquot of horse spleen ferritin $(500 \mu \mathrm{g} / \mathrm{ml})$ was incubated with $0.06 \% o$-phenanthroline (OP) and various concentrations of HA $(0,50,100,150$, or $200 \mu \mathrm{g} / \mathrm{ml})$ in phosphate-buffered saline for continuous detection for $10 \mathrm{~min}$. The development of the $\mathrm{Fe}^{2+}-\mathrm{OP}$ complex indicates the quantity of iron released from ferritin. B Effect of oxygen radical scavengers on HA-induced iron release from ferritin. A solution containing ferritin $(500 \mu \mathrm{g} / \mathrm{ml})$ and HA $(200 \mu \mathrm{g} / \mathrm{ml})$ was incubated with OP $(0.06 \%)$ and various types of oxygen radical scavengers [Tiron $10 \mathrm{mM}$, superoxide dismutase (SOD) 500 units $/ \mathrm{ml}$, or catalase $500 \mathrm{units} / \mathrm{ml}$ ] prior to the assay of iron release. Each value represents mean $\pm \mathrm{SD}$ of three separate estimations

with BDF (Lu and Lu 1987) and treatment with HA can induce lipid peroxidation in liver and blood of rats (Peng et al. 1999), suggesting a lipid peroxidation-induction capability of HA in living organisms. In the present study, we investigated the potential for HA to reduce iron and induce lipid peroxidation that may be an important toxic mechanism in vivo.

Humic acid possesses redox properties and has been shown to reduce iron(III) to iron(II) in a water-peat (slurry) system and also in iron(III)-reducing bacteria. In

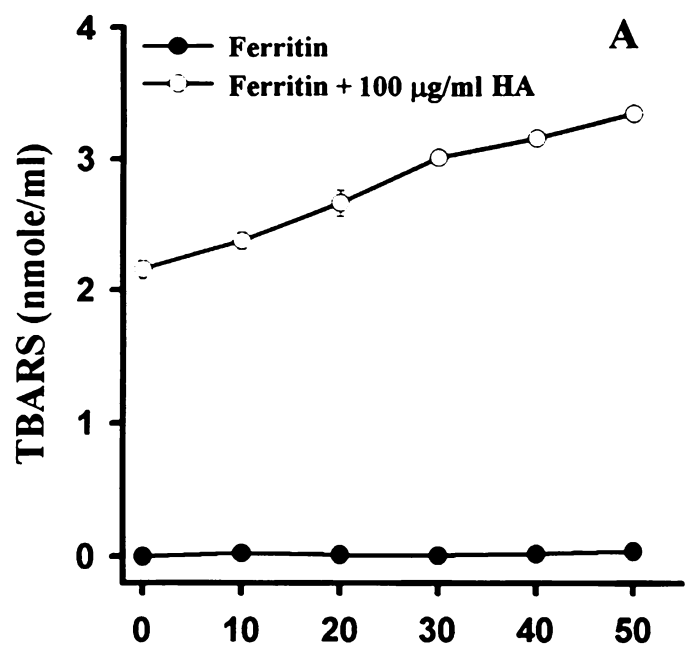

Ferritin concentration $(\mu \mathrm{g} / \mathrm{ml})$

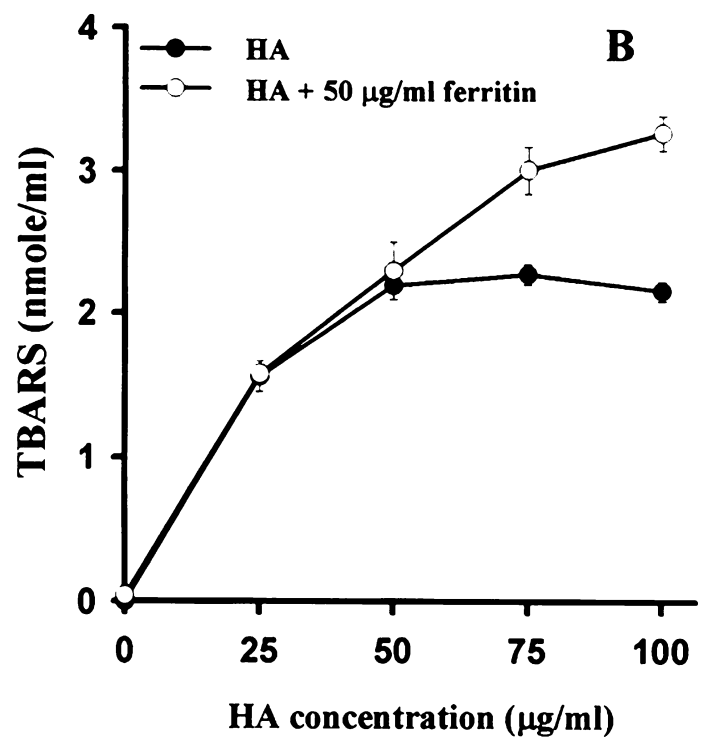

Fig. 7A,B Effect of ferritin on humic acid (HA)-induced lipid peroxidation. A Dose-dependent effect of ferritin on HA-induced lipid peroxidation. A solution containing linoleic acids $(0.4 \mathrm{mM})$ was incubated with various concentrations of horse spleen ferritin $(0-50 \mu \mathrm{g} / \mathrm{ml})$ in phosphate-buffered saline (PBS) at $37^{\circ} \mathrm{C}$ for $1 \mathrm{~h}$ in the presence or absence of HA $(100 \mu \mathrm{g} / \mathrm{ml})$ prior to assay for thiobarbituric acid-reactive substances (TBARS). B Additional effect of ferritin on HA-induced lipid peroxidation. Linoleic acids $(0.4 \mathrm{mM})$ were incubated with various concentrations of HA $(0$ $100 \mu \mathrm{g} / \mathrm{ml})$ in PBS at $37^{\circ} \mathrm{C}$ for $1 \mathrm{~h}$ in the presence or absence of horse spleen ferritin $(50 \mu \mathrm{g} / \mathrm{ml})$ prior to TBARS assay. Values are means $\pm \mathrm{SD}$ for three independent experiments

this study, we have demonstrated that HA can directly reduce iron(III) to iron(II) in aqueous conditions without the addition of any bacterium. In our reaction system, ferric ion in the HA solution may be chelated by HA. In addition, HA chelated iron in the reaction solution and reduced the redox potential of the iron(III)/ iron(II) couple, thus making the reduction reaction of 
Fig. 8 Hypothetical scheme for humic acid (HA)-induced oxidative stress

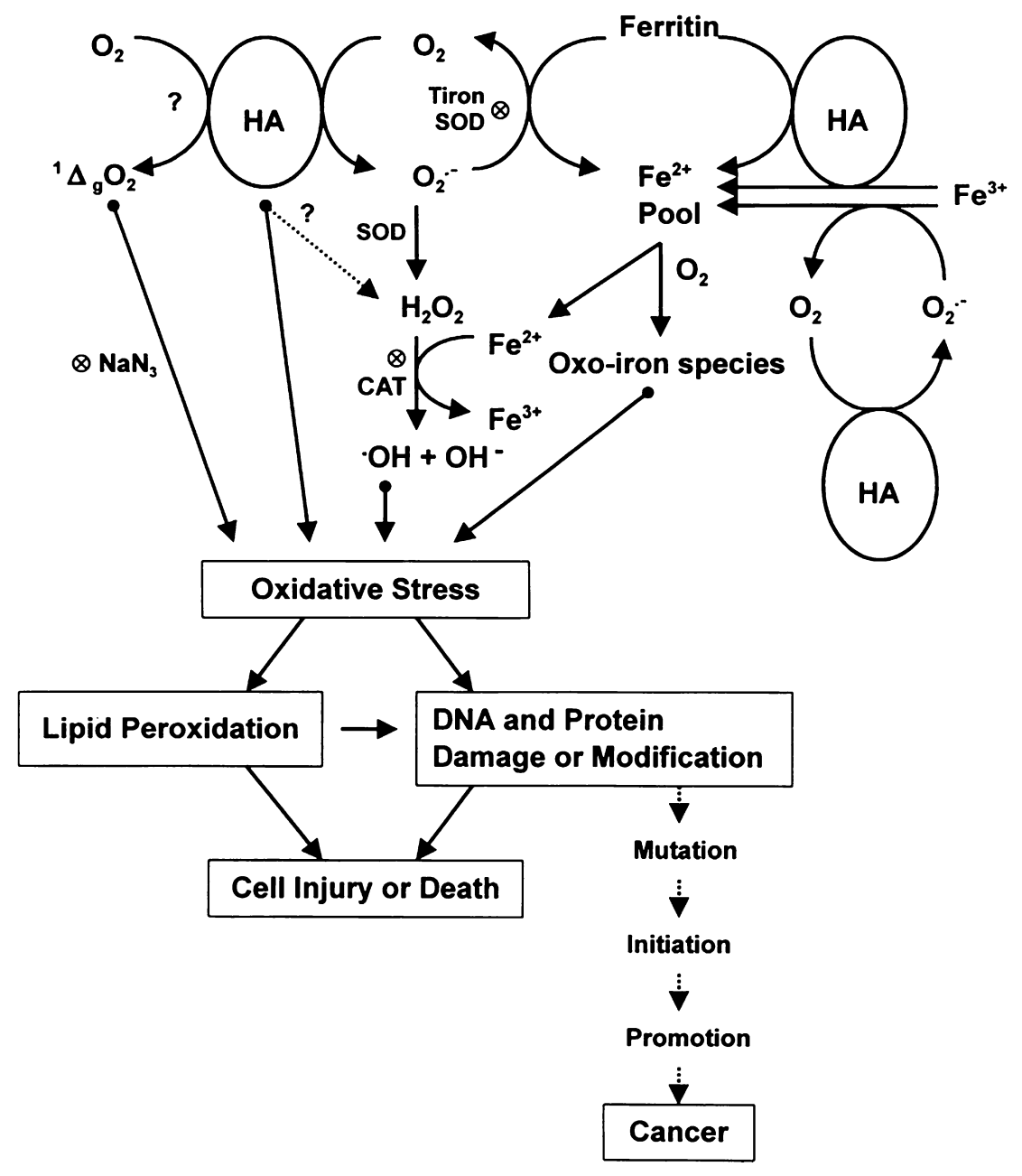

iron by HA more thermodynamically possible over a broad $\mathrm{pH}$ range. However, less iron reduction occurred at high $\mathrm{pH}$ values due to the low solubility of iron in alkaline conditions.

Our results demonstrate that the addition of HA to linoleic acids or rat liver microsomes enhances lipid peroxidation. This is consistent with our earlier studies, which suggest that incubation of cultured rabbit articular chondrocytes (Liang et al. 1998) or human erythrocytes (Cheng et al. 1999) with HA also demonstrates enhanced lipid peroxidation compared to controls. Furthermore, based on the finding that the extent of lipid peroxidation in rat liver microsomes is low at doses of HA below $30 \mu \mathrm{g} / \mathrm{ml}$, it appears appropriate to speculate whether microsomal proteins and lipids may compete to attack the same free radicals derived from HA. Humic acid-induced lipid peroxidation is partially inhibited by $\mathrm{NaN}_{3}$ or Tiron, but not by mannitol, indicating that singlet oxygen $\left({ }^{1} \Delta_{\mathrm{g}} \mathrm{O}_{2}\right)$ and superoxide $\left(\mathrm{O}_{2}{ }^{-}\right)$molecules are involved, rather than hydroxyl radicals. Nevertheless, as revealed by this present study, co-incubation of $\mathrm{NaN}_{3}$ and Tiron did not completely inhibit HA-induced lipid peroxidation. This finding may be explained by suggesting that an extra species of reactive free radical other than ${ }^{1} \Delta_{\mathrm{g}} \mathrm{O}_{2}$ and $\mathrm{O}_{2}{ }^{-}$mol- ecules, perhaps even the HA radical itself, may be involved in this process.

It has been previously reported that iron plays important roles in the initiation and propagation of lipid peroxidation (Minotti 1993). A remarkable enhancing effect of iron on the increase in HA-induced lipid peroxidation was observed in the present study. This corresponds to the results depicted in Figs. 6A and 7B, which show the increased HA-induced lipid peroxidation in terms of the release of iron from ferritin. In addition, HA, as a reductant for iron, may participate in the redox cycling of iron to maintain the appropriate ratio of iron(II)/iron(III), thus being available to initiate lipid peroxidation through the formation of oxo-iron complexes (Braughler et al. 1986).

Although iron per se may promote lipid peroxidation, the concentration of free iron in extracellular fluids has been estimated to be as low as $10^{-14} \mathrm{M}$ for iron(II) or $<10^{-17} \mathrm{M}$ for iron(III). It seems that iron-catalyzed lipid peroxidation must be preceded by a release of iron from iron storage proteins such as ferritin (Minotti 1993). The results of the present study demonstrate that the rate of iron release from ferritin is directly proportional to the amount of HA present. In addition, SOD and Tiron are able to inhibit by $48 \%$ and $33 \%$, 
respectively, the HA-mediated iron release from ferritin, indicating that HA may directly generate $\mathrm{O}_{2}{ }^{\bullet}$, which is required for iron release. This finding is also confirmed by the result of a SOD-inhibitable cytochrome $c$ reduction assay, which showed the generation of $\mathrm{O}_{2}{ }^{--}$by HA. However, the superoxide scavenger-insensitive rate of iron release from ferritin by HA is probably due to a direct reduction of ferritin iron by HA itself. By contrast to the superoxide scavengers, the addition of catalase results in a small increase in iron release, which may be explained by catalase's proclivity for inhibiting the oxidation by hydrogen peroxide $\left(\mathrm{H}_{2} \mathrm{O}_{2}\right)$ of a small amount of free iron(II) to iron(III). We speculate that $\mathrm{H}_{2} \mathrm{O}_{2}$ may be generated by the dismutation of two $\mathrm{O}_{2}{ }^{-}$molecules, or by direct two-electron transfer from HA to oxygen. The ferritin-released iron promoted the enhancement of the HA-induced lipid peroxidation, which strongly confirmed the results as discussed above. Nevertheless, low concentrations of HA, such as 25 and $50 \mu \mathrm{g} / \mathrm{ml}$, reveal no increase in HA-induced lipid peroxidation compared that occurring under control conditions. A possible explanation for this may be that the loss of lipid peroxidation caused by the competitive free-radical attack between ferritin and lipids may be compensated for by the effect of iron released by HA, this iron eliciting an increase of lipid peroxidation.

Although HA has been shown to be toxic to many mammalian cells, the mechanisms of cellular injury and oxidative damage induced by $\mathrm{HA}$ are not well understood. The possible mechanisms of HA-induced cytotoxicity are shown in Fig. 8. Humic acid is a xenobiotic radical with redox properties and has the ability to participate in many electron transfer processes through its quinone/hydroquinone redox couple. In an aqueous system, HA appears to react with oxygen to generate a series of reactive oxygen species such as ${ }^{1} \Delta_{\mathrm{g}} \mathrm{O}_{2}, \mathrm{O}_{2}{ }^{\bullet}$, and $\mathrm{H}_{2} \mathrm{O}_{2}$. Our results are in keeping with reports of previous studies suggesting that irradiation of natural waters containing humic substances promotes the system (humic substances + oxygen) to electronically exited states with higher chemical reactivity than non-irradiated controls, and yielding ${ }^{1} \Delta_{\mathrm{g}} \mathrm{O}_{2}, \mathrm{O}_{2}{ }^{\circ}$, and $\mathrm{H}_{2} \mathrm{O}_{2}$ via energy or electron transfer from HA to molecular oxygen (Slawinska and Slawinki 1975; Zepp et al. 1977; Cooper and Zika 1983). From this present study, however, we do not have strong evidence to address the question of whether HA can directly generate ${ }^{1} \Delta_{\mathrm{g}} \mathrm{O}_{2}$ and $\mathrm{H}_{2} \mathrm{O}_{2}$ under appropriate conditions. Humic acid per se and $\mathrm{O}_{2}{ }^{-}$generated by HA can reduce iron and release it from ferritin storage, which causes an increase in the "free" iron pool and perturbs the redox balance of biological systems. Subsequently, HA- and iron-induced oxidative stress results in lipid peroxidation as well as causing oxidative DNA and protein damage. If cellular antioxidant defense systems are not sufficient to protect the cell against HA-induced oxidative stress, cell damage will occur, possibly leading to death. This hypothesis was supported by our recent study suggesting that HA can increase the generation of reactive oxygen species in cultured human umbilical vein endothelial cells by enhancing the accumulation of intracellular iron (Gau et al. 2001).

Alternatively, oxidative stress may also cause carcinogenesis through the induction of DNA mutation. From several previous studies, HA has been demonstrated to be genotoxic and mutagenic to mammalian cells (Bernacchi et al. 1996; Liu et al. 1999) and to Salmonella typhimurium (Hong et al. 1991; Lu et al. 1993). An increase of free iron may also increase the chance that cancer cells will survive and flourish (Stevens et al. 1988; Toyokuni 1996). Thus, we propose that HA appears to be capable of inducing carcinogenesis, which is caused by HA- and iron-induced oxidative stress, and promoting the survival of cancer cells, this being induced by ferritin-released iron. In conclusion, the present results demonstrate that HA has the ability to reduce iron and to release it from ferritin storage as well as to promote lipid peroxidation. Humic acid coupled with released iron may perturb the redox balance and elicit an increase in oxidative stress. This may be one of the most important mechanisms for HA-mediated cytotoxicity.

Acknowledgements We thank Mr. Alex Kutlaca for his contribution to this paper. Our study was supported by Grant NSC 89-2320-B-002-103 from the National Science Council, Taiwan, Republic of China.

\section{References}

Ahmad S, Singh V, Rao GS (1995) Release of iron from ferritin by 1,2,4,-benzenetriol. Chem-Biol Interact 96:103-111

Atherton NM, Cranwell PA, Floyd AJ, Haworth RD (1967) Humic acid. I. ESR spectra of humic acids. Tetrahedron 23:16531667

Bernacchi F, Ponzanelli I, Minunni M, Falezza A, Loprieno N and Barale R (1996) In vivo cytogenetic effects of natural humic acid. Mutagenesis 11:467-469

Braughler JM, Duncan LA, Chase RL (1986) The involvement of iron in lipid peroxidation. J Biol Chem 261:10282-10289

Cheng ML, Ho HY, Chiu DT, Lu FJ (1999) Humic acid-mediated oxidative damages to human erythrocytes: a possible mechanism leading to anemia in blackfoot disease. Free Radic Biol Med 27:470-477

Chiu HC, Shih SR, Lu FJ, Yang HL (1993) Stimulation of endothelin production in cultured human endothelial cells by florescent compounds associated with blackfoot disease. Thromb Res 69:139-151

Cooper WJ, Zika RG (1983) Photochemical formation of hydrogen peroxide in surface and ground waters exposed to sunlight. Science 220:711-712

Gau RJ, Yang HL, Suen JL, Lu FJ (2001) Induction of oxidative stress by humic acid through increasing intracellular iron: a possible mechanism leading to atherothrombotic vascular disorder in blackfoot disease. Biochem Biophys Res Commun 283:743-749

Harrison PM, Arosio P (1996) The ferritin: molecular properties, iron storage function and cellular regulation. Biochim Biophys Acta 1275:161-203

Hayes MHB, MacCarthy P, Malcolm RL, Swift RS (1989) The search for structure: setting the scene. In: Hayes MHB, MacCarthy P, Malcolm RL, Swift RS (eds) Humic substances II. Wiley, New York, pp 1-6

Hong CL, Lu FJ, Lu MF, Chiang HS, Shimizu H (1991) Mutagenic screening of the active components of fluorescent humic 
substances in artesian well water of a black-foot disease endemic area in southwestern Taiwan [abstract]. Mutat Res 252:90

Huang TS, Lu FJ, Chopra IJ (1993) Inhibition of hepatic thyroxine 5 '-monodeiodinase by humic acids. Environ Toxicol Chem 12:1267-1271

Huang TS, Lu FJ, Tsai CW, Chopra IJ (1994) Effect of humic acids on thyroidal function. J Endocrinol Invest 17:787-791

Huang TS, Lu FJ, Tsai CW (1995) Tissue distribution of absorbed humic acids. Environ Geochem Health 17:1-4

Huffman JREWD, Stuber HA (1985) In: Aiken GR, Mcknight DM., Wershaw RL, MacCarthy P (eds) Humic substances in soil, sediment, and water. Wiley, New York, pp 433-582

Leenheer JA, Noyes TI (1989) Derivatization of humic substances for structural studies. In: Hayes MHB, MacCarthy P, Malcolm RL, Swift RS (eds) Humic substances II. Wiley, New York, pp $257-446$

Liang HJ, Tsai CL, Lu FJ (1998) Oxidative stress induced by humic acid solvent extraction fraction in cultured rabbit articular chondrocytes. J Toxicol Environ Health 54:477-489

Liang HJ, Tsai CL, Chen PQ, Lu FJ (1999) Oxidative injury induced by synthetic humic acid polymer and monomer in cultured rabbit articular chondrocytes. Life Sci 65:1163-1173

Liu Q, Jiao QC, Huang XM, Jiang JP, Cui SQ, Yao GH, Jiang ZR, Zhao HK, Wang NY (1999) Genotoxicity of drinking water from Chao Lake. Environ Res 80:127-31

Loveley DR, Coates JD, Blunt-Harris EL, Phillips EJP, Woodward JC (1996) Humic substances as electron acceptors for microbial respiration. Nature 382:445-448

Lowry OH, Rosebrough NJ, Farr AL, Randall RJ (1951) Protein measurement with the Folin phenol reagent. J Biol Chem 193:265-275

Lu FJ (1990a) Blackfoot disease: arsenic or humic acid? Lancet $336: 115-116$

Lu FJ (1990b) Fluorescent humic substances and blackfoot disease in Taiwan. Appl Organometallic Chem 4:191-195

Lu FJ, Lee YS (1992) Humic acid: inhibitor of plasmin. Sci Total Environ 144:135-139

Lu FJ, Liu TM (1986) Fluorescent compounds in drinking water of blackfoot disease endemic areas: animal experimental model. J Formos Med Assoc 85:352-358

Lu FJ, Lu JY (1987) Serum lipid peroxides in patients with blackfoot disease. J Formos Med Assoc 86:76-80

Lu FJ, Chiang HS, Lu MF, Shimizu H (1993) Mutagenicity of drinking well water. Bull Environ Contam Toxicol 51:545-550

Lu FJ, Lee TC, Pang VF, Huang TS (1997) Humic acid-induced testicular morphological changes in rats. Bull Environ Contam Toxicol 58:619-627

Minotti G (1993) Sources and role of iron in lipid peroxidation. Chem Res Toxicol 6:134-146

Minotti G, Aust SD (1992) Redox cycling of iron and lipid peroxidation. Lipids 27:219-226

Peng A, Wang WH, Wang CX, Wang ZJ, Rui HF, Wang WZ, Yang ZW (1999) The role of humic substances in drinking water in Kashin-Beck disease in The role of humic substances in drinking water in Kashin-Beck disease in China. Environ Health Perspect 107:293-6

Ponka P, Beaumont C, Richardson DR (1998) Function and regulation of transferrin and ferritin. Semin Hematol 35:35-54

Reif DW (1992) Ferritin as a source of iron for oxidative damage. Free Radic Biol Med 12:417-427

Reif DW, Samokyszyn VM, Miller DM, Aust SD (1989) Alloxanand glutathione-dependent ferritin iron release and lipid peroxidation. Arch Biochem Biophys 269:407-414

Rex RW (1960) Electron paramagnetic resonance studies of stable free radicals in lignins and humic acids. Nature 188: $1185-1186$

Sandell EB (1959) Colorimetric determination of trace metals. Interscience, New York

Schnitzer MT (1982) Organic matter characterization. In: Page AL (ed) Methods of soil analysis. Part 2, chemical and microbiological properties. Academic Press, New York, pp 581-594

Schnitzer M, Skinner SIM (1969) Free radicals in soil humic compounds. Soil Sci 108:383-390

Skogerbae RK, Wilson SA (1981) Reduction of ionic species by fulvic acid. Anal Chem 53:228-232

Slawinska D, Slawinki J (1975) Spectroscopic study on mild oxidation of humus acids. II. Influence of light on oxidation with molecular oxygen. Pol J Soil Sci 8:49-58

Stevens RG, Jones DY, Micozzi MS, Taylor PR (1988) Body iron stores and the risk of cancer. N Engl J Med 319:1047-1052

Szilagyi M (1973a) The redox properties and the determination of the normal potential of the peat-water system. Soil Sci 115 : 434-441

Szilagyi M (1973b) Reduction of $\mathrm{Fe}^{3+}$ ion by humic acid preparations. Soil Sci 111:233-238

Thomas CE, Aust SD (1986) Reductive release of iron from ferritin by cation free radicals of paraquat and other bipyridyl. J Biol Chem 261:13064-13070

Toyokuni S (1996) Iron-induced carcinogenesis: the role of redox regulation. Free Radic Biol Med 20:553-566

Tseng WP, Chen WY, Sung JL, Chen JS (1961) A clinical study of blackfoot disease in Taiwan, an endemic peripheral vascular disease. Mem Coll Med Natl Taiwan Univ 7:1-8

Wilson MA, Jones AJ, Williamson B (1978) Nuclear magnetic resonance spectroscopy of humic materials. Nature 276: 487-489

Worobey BL, Webster GRB (1981) Indigenous ${ }^{13}$ C-NMR structural features of soil humic substances. Nature 292:526-529

Yang HL, Lu FJ, Wung SL, Chiu HC (1994) Humic acid induces expression of tissue factor by cultured endothelial cells: regulation by cytosolic calcium and protein kinase C. Thromb Haemost 71:325-330

Zepp RG, Wolfe NL, Baughman GL, Hollis RC (1977) Singlet oxygen in natural waters. Nature 267:421-423 